\title{
Maternal mortality by direct obstetric causes in an urban referral hospital: case of Boulmiougou District Hospital in Ouagadougou, Burkina Faso
}

\section{Yobi Alexis Sawadogo ${ }^{1 *}$, Hyacinthe Zamané ${ }^{1}$, Sibraogo Kiemtoré1, Sansan Rodrigue Sib ${ }^{2}$, Dantola Paul Kain ${ }^{1}$, Issa Ouédraogo ${ }^{1}$, Adama Ouattara ${ }^{1}$, Charlemagne Ouédraogo ${ }^{1}$, Ali Ouédraogo ${ }^{1}$}

\begin{abstract}
${ }^{1}$ Department of Obstetrics and Gynecology, Unity of Training and Research in Health Sciences of University Ouaga I Professor Joseph Ki-Zerbo, Ouagadougou, Burkina Faso

${ }^{2}$ Department of Obstetrics and Gynaecology of High School of Health Sciences, University of Ouahigouya, Burkina Faso
\end{abstract}

Received: 16 April 2019

Accepted: 12 June 2019

\section{*Correspondence:}

Dr. Sawadogo Yobi Alexis,

E-mail: sawalexis@yahoo.fr

Copyright: ( ) the author(s), publisher and licensee Medip Academy. This is an open-access article distributed under the terms of the Creative Commons Attribution Non-Commercial License, which permits unrestricted non-commercial use, distribution, and reproduction in any medium, provided the original work is properly cited.

\section{ABSTRACT}

Background: Complications during pregnancy and childbirth are the leading causes of death and disability for women of childbearing age. Objective of this study was to study maternal mortality of direct obstetric origin at the Boulmiougou district hospital from 2010 to 2014.

Methods: This was a retrospective cross-sectional descriptive and analytical study of maternal deaths by direct obstetric cause at the maternity ward of Boulmiougou District Hospital during the period from January $1^{\text {st }} 2010$ to December $31^{\text {st }}$, 2014, i.e. 5 years.

Results: The maternal mortality rate by direct obstetric cause of 147.68 maternal deaths per 100,000 live births. The average age of the patients was 27.09 years old. The direct causes of maternal death were hemorrhage $(47.06 \%)$, hypertensive disorders $(20.59 \%)$, infections $(14.71 \%)$ and unsafe abortion (11.76\%). Contributing factors to maternal deaths were delay in evacuation $(47.06 \%)$ and delay in care $(38.23 \%)$.

Conclusions: Maternal mortality remains high in the Boulmiougou District Hospital. To effectively combat maternal mortality, it is important to focus on the continuous training of staff and the strengthening of the technical platform.

Keywords: Boulmiougou, Maternal mortality, Obstetric cause, Ouagadougou

\section{INTRODUCTION}

Maternal mortality remains a major challenge for health systems around the world. ${ }^{1}$ According to WHO, about 830 women die every day in the world because of complications related to pregnancy or childbirth. In 2015, 303,000 women died during or after pregnancy or childbirth. Most of these deaths occurred in low-income countries and most could have been prevented. ${ }^{2}$ Maternal mortality is a social tragedy and constitutes a real public health problem. It is an indicator of the quality and supervision of obstetric care in a country., At the hospital level, it may be a witness to the quality of care supervision before, during and after delivery. ${ }^{3}$

Complications during pregnancy and childbirth are the leading causes of death and disability for women of childbearing age. ${ }^{5}$ 
In Burkina Faso, according to the 2010 Demographic and Health Survey (DHS), a woman dies as a result of a pregnancy-related complication every five hours. The maternal mortality ratio was 341 per 100,000 births in 2010, which is far from the Millennium Development Goals of 176.70 deaths per 100,000 live births for 20156; also, direct and preventable obstetric causes are responsible for about $80 \%$ of these deaths (haemorrhages, infections and dystocia etc.). ${ }^{7}$ In 2014 , there was an overall obstetric case fatality rate of $2.01 \%$ at the national level, $4.65 \%$ at the hospital level and $1.69 \%$ at the district level. Specifically, this rate was $0.49 \%$ at Bogodogo District Hospital, $1.25 \%$ at Boulmiougou District Hospital and $5.09 \%$ at Yalgado OUEDRAGO University Hospital. $^{8}$

These data are well above the WHO threshold of $1 \%$. The high mortality in our context, could be explained by a low access of women to emergency obstetric care, an inadequacy of this care (for lack of qualified human and material resources, the 3 delays (delay in decision making, delay in evacuation, delay of care). Several strategies have been developed to improve maternal health in the world, in Africa and particularly in Burkina Faso. They were aimed at improving the performance of care through three mechanisms: strengthening the skills of providers, the establishment of an effective referral system and the availability of emergency kits.

Among the actions developed in Burkina Faso we can mention inter alia the implementation of National Health Development Plans (PNDS) 2001-2010 and 2011-2020, the implementation of the plan to accelerate the reduction of maternal mortality in 2006, the implementation of reproductive health plans and programs at regional and national levels, the adoption and implementation of Emergency Obstetric and Neonatal Care (SONU) in 2006, the implementation of programs to improve the quality and access to emergency obstetric care in developing countries. ${ }^{9,10}$

Despite all these efforts, it is clear that women still lose their lives as a result of direct complications related to their pregnancy in different hospitals in Burkina Faso, including the Boulmiougou District Hospital. This sad reality challenges us. According to Margaret et al, information on maternal mortality ratios and trends is essential for resource mobilization, planning and assessment of progress 1 .

That is why it seemed important to study the lethality of obstetric complications at the Boulmiougou district hospital, including epidemiological aspects, causes analysis and identification of contributing factors, in order to propose actions to help reduce its rate.

\section{METHODS}

It was a retrospective cross-sectional descriptive and analytical study on cases of maternal deaths of direct obstetric cause at the maternity hospital of Boulmiougou District Hospital during the period of 2010-2014, ie 5 years. In the health system in Burkina Faso, the District hospital is the first reference level of patients. These hospitals may, in turn, refer patients to regional or university hospitals.

The study population was all maternal deaths by direct obstetric cause occurring at the maternity of Boulmiougou District Hospital. Our sample included patients who died by direct obstetric causes at the Boulmiougou District Hospital during the period from January $1^{\text {st }} 2010$ to December $31^{\text {st }}, 2014$ and whose records were exploitable. A pre-established form served as a data collection medium. Data sources included clinical records, birth records and operating room registers.

The overall lethality rate of obstetric complications was calculated as well as the specific lethality by type of complication.

\section{The variables assessed were}

- Sociodemographic data (marital status, geographical origin and the circumstances of admission)

- The clinical characteristics of the deceased women (gestational age, monitoring of pregnancy, general condition, the mode of termination of the pregnancy, the moment of death, causes of death)

- Therapeutic decisions (the mode of delivery, the treatment established) and the follow-up of the care

- The delay of taking care and the delay of death occurrence

- Assessment of three delays.

\section{Statistical analysis}

The data analysis was done using the software Epi info in version 7.1.1. The Chi-2 test and Student test were used to determine the factors contributing to maternal mortality. A value of $\mathrm{p}$ less than 0.05 for Chi-2 test was considered significant.

\section{RESULTS}

\section{Epidemiological aspects}

During the study period we collected 34 maternal deaths by direct obstetric causes for 23450 deliveries including 23023 live births. The ratio of maternal mortality by direct obstetric cause was 147.68 maternal deaths per 100,000 live births with an average of 6.8 maternal deaths per year. The maternal mortality ratio ranged from 85.4 to 226.18 per 100,000 live births from 2010 to 2014 . The low rate was for the year 2010 and the high rate for the year 2011. The annual change in the maternal mortality ratio at Boulmiougou District Hospital from 2010 to 2014 was shown in Table 1 . 
Table 1: Evolution of maternal mortality ratio per year.

\begin{tabular}{|llll|}
\hline Year & Maternal deaths & Live births & Maternal mortality ratio per 100000 live births \\
\hline 2010 & 3 & 3513 & 85.4 \\
\hline 2011 & 9 & 3979 & 226.2 \\
\hline 2012 & 10 & 4542 & 220.2 \\
\hline 2013 & 7 & 5185 & 135 \\
\hline 2014 & 5 & 5804 & 86.1 \\
\hline Total & 34 & 23023 & 147.7 \\
\hline
\end{tabular}

Regarding the calculation of the case fatality rate, we did not take into account the medical records for the years 2010, 2011 and 2012. These records were incomplete. For 2013 and 2014, we counted 12 maternal deaths for 751 cases of direct obstetric complications. The overall case fatality rate for obstetric complications was $1.6 \%$. Haemorrhage was the main cause of death with 7 cases on 10. The other causes represented one case each. Table 2 gives the lethality of the main direct obstetric complications. Lethality according delivery route was also calculated. Caesarean section had a higher fatality rate than vaginal delivery. It is presented in Table 3.

Regarding the women characteristics, age was not specified in one woman. The average age was 27.09 years with extremes of 16 and 42 years. Of 33 cases of maternal deaths, $21(63.6 \%)$ were under 30 years old. More than three quarters $(75.9 \%)$ of the patients lived in urban areas; $24.1 \%$ lived in rural areas. We have divided the patients according to whether they performed a gainful activity or not. Women who did not perform a gainful activity accounted for $97.1 \%$ (33 cases) of the women. The average parity was 2.22 deliveries, with extremes of 0 and 9 . Table 4 presents the distribution of dead women by socio-demographic characteristics.

Table 2: lethality by direct obstetric complication from 2013 to $2014(n=10)$.

\begin{tabular}{|llll|}
\hline Pathology & $\begin{array}{c}\text { Number } \\
\text { of cases }\end{array}$ & $\begin{array}{l}\text { Number of } \\
\text { deaths }\end{array}$ & Lethality \\
\hline $\begin{array}{l}\text { Pregnant- } \\
\text { puerperal } \\
\text { infections }\end{array}$ & 35 & 1 & 2.9 \\
\hline Hemorrhage & 206 & 7 & 3.4 \\
\hline Eclampsia & 105 & 1 & 1 \\
\hline Abortion & 21 & 1 & 4.8 \\
\hline
\end{tabular}

Table 3: Lethality according to delivery route $(n=25)$.

\begin{tabular}{|c|c|c|c|}
\hline $\begin{array}{l}\text { Delivery } \\
\text { route }\end{array}$ & $\begin{array}{l}\text { Women } \\
\text { died }\end{array}$ & $\begin{array}{l}\text { Living women } \\
\text { alive }\end{array}$ & Lethality \\
\hline C-section & 6 & 2140 & $0.3 \%$ \\
\hline $\begin{array}{l}\text { Vaginal } \\
\text { delivery }\end{array}$ & 19 & 21285 & $0.1 \%$ \\
\hline Total & 25 & 23425 & $0.1 \%$ \\
\hline
\end{tabular}

Table 4: Distribution of dead women by sociodemographic characteristics $(n=34)$.

\begin{tabular}{|c|c|c|}
\hline Characteristics & Number & Percentage \\
\hline \multicolumn{3}{|l|}{ Age } \\
\hline$<20$ years & 6 & 17.6 \\
\hline $20-24$ years & 7 & 20.6 \\
\hline $25-29$ years & 9 & 26.5 \\
\hline $30-34$ years & 7 & 20.6 \\
\hline$>34$ years & 6 & 14.7 \\
\hline \multicolumn{3}{|l|}{ Place of residence } \\
\hline Urban area & 26 & 76.5 \\
\hline Rural area & 8 & 23.5 \\
\hline \multicolumn{3}{|l|}{ Marital status } \\
\hline Marital life & 30 & 88.2 \\
\hline Single & 4 & 11.8 \\
\hline \multicolumn{3}{|l|}{ Socio-professional status } \\
\hline Non-remunerative activity & 33 & 97.1 \\
\hline Remunerative activity & 1 & 2.9 \\
\hline \multicolumn{3}{|l|}{ Parity } \\
\hline Pauciparous & 16 & 47.1 \\
\hline Nulliparous & 7 & 20.6 \\
\hline Primiparous & 5 & 14.7 \\
\hline Multiparous & 5 & 17,6 \\
\hline
\end{tabular}

Table 5: Distribution of dead women according to motif of admission $(n=34)$.

\begin{tabular}{|lll|}
\hline Motif of admission & Number & Percentage \\
\hline Childbirth & 9 & 26.5 \\
\hline Hemorrhage & 6 & $17.6 \%$ \\
\hline Preeclampsia & 6 & $17.6 \%$ \\
\hline Abortion & 3 & $8.8 \%$ \\
\hline Anemia & 2 & $5.9 \%$ \\
\hline Others* & 8 & $23.5 \%$ \\
\hline Total & 34 & $100 \%$ \\
\hline
\end{tabular}

*Chest pain (1), dyspnea (1), Excessive uterine height (1), Infection (1), Threat of premature labour (1), loss of Consciousness (1), vicious presentation (1), Pregnancy vomiting (1).

\section{Clinical and therapeutic aspects}

Patients were admitted by reference in $55.9 \%$ of cases (19/34). The others patients were self-referrals (44.1\%). 
Among the referred patients, 16 came from a first level health centre, 2 patients came from a medical centre and one patient came from a private facility.

Childbirth was the main reason for admission with $26.47 \%$ followed by haemorrhage and hypertensive disorders with $17.65 \%$ each. The motifs of admission are presented in Table 5.

The assessment of the general condition was noted in twenty-three (23) cases. Patients who died had a poor general condition in 10 cases $(43.5 \%)$, a good general condition in 7 cases $(30.4 \%)$, and a fairly good general condition in 6 cases $(26.1 \%)$.

With regard to the consciousness status, 17 patients had a normal consciousness $(73.9 \%)$, four (04) were obsessed or $17.4 \%$ and 02 patients were in coma or $8.7 \%$ of cases.

At admission, of the women who died, 8 were in the postpartum period, 15 women were in the third trimester of pregnancy and 4 were in the first trimester of pregnancy. In 7 women the gestational age was not specified.

Table 6: Distribution of dead women according to the diagnoses made at admission $(n=26)$.

\begin{tabular}{|ll|l|}
\hline Diagnosis retained & Number & Percentage \\
\hline Childbirth & 9 & 34.6 \\
\hline Preeclampsia, eclampsia & 5 & 23.1 \\
\hline Complications of abortion & 4 & 15.4 \\
\hline Infections & 3 & 11.5 \\
\hline Postpartum hemorrhage & 2 & 7.7 \\
\hline Antepartum hemorrhage & 1 & 3.9 \\
\hline Obstetric shock & 1 & 3.9 \\
\hline Total & 26 & $100 \%$ \\
\hline
\end{tabular}

After physical examination and paraclinical assessment, the diagnoses retained were labour, preeclampsia / eclampsia, abortion complications and infections with $34.6 \%, 23.1 \%, 15.4 \%$ and $11.5 \%$, respectively. The different diagnoses are listed in the Table 6.

With regard to the therapeutic management, it should be noted that with regard to the therapeutic management, it should be noted that the time of first contact with the caregiver was ranged from 0 to 30 minutes with an average delay of 5.12 minutes for 25 patients. The time between admission and the moment of first contact was not specified for 9 women. Twenty-one (21) women ( $84 \%$ of the cases) had undergone a clinical examination within 15 minutes of their arrival in the emergency room, and 4 women $(16 \%)$ had undergone clinical examination in 15 to 30 minutes.

The delay of care could not be specified in 13 women. Patients in whom this delay has been specified, care began within 0-45 minutes with an average delay of 10.6 minutes. In $90.5 \%$ of the cases $(19 / 21)$, treatment was given within 30 minutes after the first contact with the nursing staff. In $9.5 \%$ of cases $(2 / 21)$, women waited between 30 minutes to 1 hour.

Surgery was indicated in 7 patients. The time between the indication and the beginning of the surgery exceeded 1 hour in all patients (70 to 95 minutes).

Six (06) women needed a blood transfusion but only 04 actually benefited but the quantities were less than the actual needs.

\section{Death data}

Deaths occurred in the postpartum period $67.7 \%$ (23 cases), in the pregnancy period $20.6 \%$ ( 7 cases) and in the post-abortion suites $11.8 \%$ ( 4 cases). Table 7 shows the distribution of dead women according to the outcome of pregnancy.

Table 7: Distribution of dead women according to the outcome of pregnancy.

\begin{tabular}{|lll|}
\hline Pregnancy outcome & Number & Percentage \\
\hline Vaginal delivery & 16 & 47.06 \\
\hline Fetus no expelled & 7 & 20.59 \\
\hline C-section & 6 & 17.65 \\
\hline Abortion & 4 & 11.76 \\
\hline Laparotomy (uterine rupture) & 1 & 2.94 \\
\hline Total & 34 & 100 \\
\hline
\end{tabular}

The time between patient admission and death was also calculated. The average overall time was 22 hours 27 minutes. Relative to the admission time, the death occurred in less than one hour in 8 cases, between 1 hour and 24 hours in 13 cases and more than 24 hours in 9 cases.

Table 8: Distribution of dead women according to the obstetric causes $(n=34)$.

\begin{tabular}{|lll|}
\hline Obstetric causes & Number & Percentage \\
\hline Hemorrhage & 16 & 47.1 \\
\hline Complications of preeclampsia & 7 & 20.6 \\
\hline Obstetric infections & 5 & 14.7 \\
\hline Complications of abortion & 4 & 11.8 \\
\hline Dystocia & 2 & 5.9 \\
\hline Total & 34 & 100 \\
\hline
\end{tabular}

The causes of maternal deaths were assessed. Haemorrhage was the first cause with $47.1 \%$. The other causes were preeclampsia/eclampsia, infection with $20.6 \%$ and $14.7 \%$. The distribution of dead women by obstetric cause is presented in Table 8 .

Contributing factors of death were identified after univariate analysis. During the study, there were 6 postcaesarean deaths out of 2146 or $0.28 \%$, compared to 16 
deaths following vaginal delivery in 21304 , ie. $0.08 \%$ (p $<0.05)$. The distribution of contributing factors to the occurrence of maternal deaths has been reported in Table 9.

Table 9: Factors associated to occurrence of maternal deaths.

\begin{tabular}{|lll|}
\hline Contributing factors & Number & Percentage \\
\hline Delay to evacuation & 16 & 47.06 \\
\hline $\begin{array}{l}\text { Delay to support decision } \\
\text { making }\end{array}$ & 13 & 38.23 \\
\hline Delay in giving care & 8 & \\
\hline Lack of blood & 2 & \\
\hline Care served too later & 1 & 14.71 \\
\hline Blood transfusion trouble & 1 & \\
\hline $\begin{array}{l}\text { Delay in treatment } \\
\text { prescription }\end{array}$ & 1 \\
\hline $\begin{array}{l}\text { Delay to medical } \\
\text { consultation }\end{array}$ & 5 \\
\hline Pregnancy without follow up & 3 \\
\hline Lack of financial means & 2 \\
\hline
\end{tabular}

\section{DISCUSSION}

The ratio of maternal mortality by direct obstetric cause was 147.7 maternal deaths per 100,000 live births. This rate is higher than that of Chelli et al in Tunisia. ${ }^{11}$ However, it is lower than those of Foumsou in Chad, Fomulu in Cameroon and Igberase in Nigeria, which were respectively 968, 365 and 2232 per 100,000 live births. ${ }^{12-14}$ This ratio is comparable to the average estimated for the West Africa region according to Filippi et al, and those of other authors in the same region. ${ }^{9,10,16}$ This difference in ratio could be explained by the technical level of hospitals (level 2 versus level 3 ). In addition, the establishment of maternal death audit sessions could have contributed to improving the quality of care in this institution.

The average age in this series was 27.09 years. This result is superior to that of Foumsou et al, in N'Djamena. ${ }^{13}$ This average is lower than that of several other authors who varies between 28.2 and 33 years..$^{5,11,12,15}$ The frequent early marriages in our area could explain this average age. Housewives who did not engage in gainful employment accounted for $95.45 \%$ of the women who died in our study. Poverty, ignorance, the very difficult living conditions of housewives could explain this very high proportion of housewives among the deceased.

The maternal mortality ratio has decreased from 2012 it has increased from 220.2 per 100,000 births to 135 in 2013 and to 86,1 in 2014. Similarly, the case fatality rate of obstetric complications has increased from $2,3 \%$ in 2013 to $1.1 \%$ in 2014. Effective implementation of emergency obstetric care after strengthening the operational capacity of the hospital could be the reason. During this period, in addition to the training of personnel in emergency obstetric and neonatal care, the number of gynaecologists-obstetricians went from 3 to 6 and that of midwives / maieutic from 41 to 65 .

The causes of mortality found are classic. Haemorrhage was the first cause and accounted for $47.1 \%$. This result fits with those of several authors but the proportions are variable. ${ }^{4,5,11,12,15,16}$ Haemorrhage remains an important factor in maternal morbidity and mortality in developing countries due to lack of blood products and preventive measures in hospitals in these countries.

For Igberase and Ebeigbe, the most common causes of maternal mortality were puerperal sepsis, abortion complications, pre-eclampsia/eclampsia, prolonged obstructed labour, haemorrhage accounting for $33 \%$, $22.6 \%, 17.4 \%, 13.0 \%$ and $7.8 \%$, respectively. ${ }^{14}$

Hypertensive complications ranked $2^{\text {nd }}$ with $20.59 \%$. This same rank was found by Filippi, Chelli and Thiam. ${ }^{11,15,16}$ In Foumsou's study in Chad, this pathology was the leading cause of maternal death. ${ }^{13}$ The popularization of focused antenatal care and women's adherence to this care could make it possible to detect these pathologies early and take care of them in time.

Infections ranked 2nd in most studies in sub-Saharan Africa is in $3^{\text {rd }}$ place in our series with $14.71 \%$ as in that of Foumsou in Chad. ${ }^{4,12,13}$ Compliance with the prevention of infection during delivery, screening and treatment of genital infections during pregnancy would have significantly reduced this condition.

In addition, the study identified factors that likely contributed to maternal mortality. Indeed, the mortality rate for women who had a caesarean section was 3.5 times that of women who gave birth vaginally $(p<0.05)$. This finding could be explained by the risk of haemorrhage and infectious diseases, which are often higher during caesareans carried out urgently on parturient who have been referred or who have been treated late.

The 3 delays are known for their contribution to maternal morbidity and mortality. In our series, the delay in evacuation was noted in $47.06 \%$ of the cases of death and the delay in the decision to take care in $38.23 \%$ of the cases. Foumsou had found the delay in consultation as a contributing factor to maternal mortality in $67.4 \%$ of cases. ${ }^{13}$ The delay in taking care could be explained by the deficiency of the technical platform, the lack of transfusion products and the lack of qualified personnel available at the opportune moment of taking care. Indeed, because of the workload, some patients had to wait a long time before receiving first care.

\section{CONCLUSION}

Maternal mortality by direct obstetric cause remains a major concern at the Boulmiougou District Hospital. The 
main causes are haemorrhage, preeclampsia and its complications and finally infections. The majority of these deaths could be avoided with a strengthening of competent providers in obstetrics and a better organization of care. We believe that introducing free obstetric and neonatal care could help reduce this tragedy.

\section{Funding: No funding sources}

Conflict of interest: None declared

Ethical approval: The study was approved by the Institutional Ethics Committee

\section{REFERENCES}

1. Hogan MC, Foreman KJ, Naghavi M, Ahn SY, Wang M, Makela SM, et al. Maternal mortality for 181 countries, 1980-2008: a systematic analysis of progress towards Millennium Development Goal 5. The Lancet. 2010;375(9726):1609-23.

2. WHO (2018) Maternal Mortality published on 18 February 2018 Available at: http://www.who.int/en/news-room/fact-sheets/detail/ maternal-mortality.

3. Bohoussou KPE, Guié P, Oyéladé M, N'guessan, Anongba S, Toure K. Evolution of maternal mortality at the maternity hospital of Treichville University Hospital in Abidjan from 2005 to 2009. Journal of SAGO. 2012;13:1.

4. Ouedraogo I, Sib SR, Kiemtoré S, Sawadogo Y, Kain DP, Zamané H, et al. Maternal mortality in the obstetrics and gynecology service of regional hospital center of ouahigouya: epidemiological, etiological aspects and contributing factors-about 151 cases collected in three years from 1st January 2013 to 31 December 2015. Open J Obstet Gynecol. 2017;7:447-54.

5. Mukendi MR, Balloy KM, Ngwe TMJ, Kalenga MK. Study of maternal mortality and factors associated with the Jason Sendwe Hospital in Lubumbashi, Congo from 2000 to 2010. Medical Review of the Great Lakes. 2012;1(2):104.

6. WHO. Millennium Development Goal: Goal 5, Improve maternal health. United Nations Department of Public Information - DPI / 2517 E: 2010.

7. Kaboré S, Méda CZ, Sombié I. Fight against maternal mortality in rural areas: decentralization of the supply of emergency obstetric care in Burkina Faso. The Pan African Med J. 2017;27:236.

8. Ministry of Health Burkina Faso / Directorate General of Studies and Sectoral Statistics. Statistical Yearbook. 2014:330.
9. Ministry of Health Burkina Faso. Program for improving the quality and access to emergency obstetric care in developing countries Project FSP 2001-149 - MAE-F Component 2 Burkina Faso Final Activity Report January 1, 2003 to March 31, 2006.

10. Ministry of Health Burkina Faso. National Health Development Plan, (2011-2020): 2011:56.

11. Chelli D, Dimassi K, Zouaoui B, Sfar E, Chelli H, Chennoufi MB. Evolution of maternal mortality in a level 3 Tunisian maternity from 1998 to 2007. J Gynecol Obst Biol Reprod. 2009;38(8):655-61.

12. Fomulu JN, Ngassa PN, Nong T, Nana P, Nkwabong E. Maternal mortality at the maternity of Yaoundé University Hospital, Cameroon: A 5 year retrospective study (2002 to 2006). Health Sci Say. 2009;10(1):1-6.

13. Foumsou L, Saleh A, Kaïmba O, Djongali S, Djimté N, Mignagnal K. Determinants of maternal mortality at N'Djamena General and National Reference Hospital -Chad. Dissemination and Valorisation of the Results of Scientific and Technical Research of the CNAR. 2010;7:1-7.

14. Igberase GO, Ebeigbe PN. Maternal mortality in a rural referral hospital in the Niger Delta, Nigeria, J Obstet Gynaecol. 2017;3:275-8.

15. Thiam O, Cisse ML, Niang M, Diouf A, Gaye A, Moreau JC. Maternal mortality at King Baudouin Health center in Dakar (Senegal). Mali Medical. 2014;29(3):17-21.

16. Filippi V, Cabbage D, Ronsmans C, Graham W, Sayet. Levels and Causes of Maternal Mortality and Morbidity. In: Black RE, Laxminarayan R, Temmerman M, et al., Editors. Reproductive, Maternal, Newborn, and Child Health: Disease Control Priorities, Third Edition (Volume 2). Washington, DC: The International Bank for Reconstruction and Development / The World Bank. 2016:3. Available at: https://www.ncbi.nlm.nih.gov /books/NBK361917/.

Cite this article as: Sawadogo YA, Zamané $\mathrm{H}$, Kiemtoré S, Sib SR, Kain DP, Ouédraogo I, et al. Maternal mortality by direct obstetric causes in an urban referral hospital: case of Boulmiougou District Hospital in Ouagadougou, Burkina Faso. Int J Reprod Contracept Obstet Gynecol 2019;8:3009-14. 